\title{
A Study Of Indonesian Host Country Nationals' Perspectives: What Expatriates Should Know
}

Roger C. Russell, Ph.D., Crandall University, Canada

Catherine E. Aquino-Russell, Ph.D., University of New Brunswick, Canada

\begin{abstract}
Expatriates live many paradoxical experiences while being immersed in another culture (Russell, 2006; Osland \& Osland, 2006; Russell \& Dickie, 2007; Russell \& Aquino-Russell, 2010; 2011). This led us to wonder what it might be like for host country nationals (HCNs) to work with expatriates in their own country. There is literature describing the changing of business, communication, and cultural practices so that expatriates can be more successful and more culturally congruent (Selmer, 2000; Banuta-Gomez, 2002; Montagliani \& Giacalone, 1998; Hawkins, 1983; Peppas, 2004), but is this really happening from the HCN's perspectives? This study focused on describing the lived experience of Indonesian employees using their own words. Written descriptions were analyzed/synthesized using Giorgi's descriptive phenomenological method (Giorgi, 1975; 1985; 2009; Giorgi \& Giorgi, 2003). The central finding points to a 'disconnect' between two worlds and paradoxical ways of being for Indonesians while working for Western-based organizations at home. The new knowledge may enhance knowledge for managers which could in turn alter management practices in relation to valuing HCNs for their contributions to Western organizations.
\end{abstract}

Keywords: Indonesian Expatriates; Expatriate Cross-Cultural Interaction

\section{INTRODUCTION}

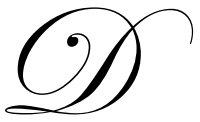

ue to ongoing globalization, being immersed in another culture is an experience lived by a growing number of individuals worldwide and will continue in the decades to come (Varma, Pichler, \& Budhwar, 2011). This means more and more individuals engage in international activities that result in increased contact with persons from different cultures. Yet, while expatriates have been widely studied, it is surprising to discover "that the perspective of host country nationals (HCNs) has not yet received extensive study" (Templar, 2010, p.1754).

The research participants in this current study are Indonesian and the researchers are Canadian. The magnitude and importance of cross-cultural interaction between the two countries has been occurring for decades. Since 1949, when Canada and Indonesia first exchanged resident Ambassadors, both countries have had active relationships with each other; including "development co-operation, investment in the resource sector, [with] ... a growing level of trade" (Centre for Intercultural Learning, 2000, p. 160). The relationship has been productive as indicated by the fact that "cumulative Canadian direct investment in Indonesia is estimated at $\$ 8$ billion" (The Indonesia Canada Chamber of Commerce, 2000, p. 28). Direct investment in 2007 was almost 2.1 billion dollars (Government of Canada, 2010). There is little doubt that Canadian and other Western-based organizations will continue to do business in Indonesia and ensuring that Canadians understand their Indonesian colleagues' experiences is vital.

There has been research focusing on what it is like for expatriates to be immersed in another culture (Russell, 2006). Westerners experience many paradoxical experiences when living and working away from home 
and the organizational culture changes because of a blending of Western and Indonesian values (ibid). We have not found literature to date related to what the experience might be like for Indonesians to work in Western-based organizations while still living in their home country.

The study is unique and differs from conventional approaches described in the literature (Loiselle \& Profetto-McGrath, 2004; Romyn, 2001). It seeks to build on a qualitative research program of lived experiences, and interest in the experience of being immersed in another culture (Aquino-Russell, 2003, Russell, 2006; Russell \& Dickie, 2007; Aquino-Russell \& Russell, 2009; Russell \& Aquino-Russell, 2010; 2011). This phenomenological research will be directed by the following question: What is the general structural description (or meaning) of the experience of working in Western-based organizations for Indonesians? The objectives of this study were:

- $\quad$ to describe the meaning of the experience of working in Western-based organizations for Indonesians while in Indonesia, and

- $\quad$ to enhance the understanding of the similarities and differences in working for Western-based versus Indonesian organizations as perceived by Indonesians.

Understanding the experiences and perceptions of the Indonesians who work for Western-based organizations is important as it will offer cultural insights related to current management practices. This is turn may lead to the potential for altering practices to enhance the effective management of Indonesian employees who are valuable component of success for many Western-based organizations.

\section{LITERATURE REVIEW}

The working life of the expatriate manager is about the fascinating challenges involved in "being caught between the contradictory demands of the headquarters on the one hand and the demands of the host country nationals and the local situation on the other" (Osland \& Osland, 2006, p. 95). This intriguing balancing of two worlds has led to considerable research completed on expatriation (Mendenhall, Kuhlmann, Stahl, \& Osland, 2002; Hutchings, 2005; Bonache, Brewster, \& Suutari, 2001; Osland, 2000; Shim \& Paprock, 2002; Tung, 1988; Varner \& Palmer, 2002). However, precious little research has been completed from the perspective of HCNs (Vo, 2009; Tarique, Schuler, \& Gong, 2006; Toh \& DeNisi, 2003). It is believed that the lack of interest in the research community about HCNs stems from a longstanding "ethnocentric belief that the success of an expatriate assignment depends solely on expatriates" (Bartlett, Lawler, Bae, Chen, \& Wan, 2002, p. 385). Varma, Pichler, and Budhwar (2011) concur with this assertion and Toh and DeNisi (2003) added that the "existing IHRM [international human resource management] studies have neglected the HCN's role in the success of expatriate assignees, placing the burden largely on the expatriate" (p. 617). Clearly there has been a persistent management view that HCNs were not very important in the bigger scheme of things (Mendenhall, Punnett, \& Ricks, 1995) and this is reflected by the lack of research activity.

For the purpose of this current research, it is central to recognize that HCNs represent a critical component of any business venture as a "facilitating or hindering factor in the expatriate adjustment process" (Toh \& DeNisi, 2003, p. 617) and "for increasing [organizational] effectiveness in the host nation" (Mahajan, 2011, p.121). Lee \& Sukoco (2010) added that"developing and maintaining relationships with [HCNs], are the core facets of expatriate performance" (p. 966). This explains why Takeuchi (2010) made it clear that "there is a surprising lack of attention to the development needs and potential contributions of the HCN workforce associated with the expatriate management assignment" (p.1060). Also intriguing is the fact that "the majority of studies on [HCNs] consider the influence of HCNs on expatriates but not vice versa" (Takeuchi, 2010, p. 1050).

So the current situation is that the HCN perspective is a research focus largely unexplored in the literature (Bartlett, Lawler, Bae, Chen, \& Wan, 2002). In particular, there is little knowledge about the HNC perspective on employer programs including training and development, and also, for example, limited evidence exists that explores the reactions of HCNs to "ethnocentric pay policies" (Mahajan, 2011, p.121). The importance of understanding HNCs' perspective is highlighted by a recent trend to hire local HNCs in an attempt to "move away from decades of expensive and failed" (Owen, 2010, p.100) expatriation assignments. 
The needs of Western-based organizations, combined with the literature's shortcomings, have led directly to "a growing call for a refocusing of international management research on the needs and contributions of HCNs" (Vance, Vaiman, \& Andersen, 2009, p. 651). To more fully understand this phenomenon, it was essential to obtain HCNs' own thoughts of their lived experiences while working with Western-based organizations. According to the literature, lived experience is the world as persons directly experience it and describe it (van Manen, 1990). It is a very significant phenomenon for study as pointed out by Keen (1975) who wrote that "the lived experience must be our guide in understanding other people and what things mean to them" (p. 21).

\section{METHODOLOGY}

The research strategy used in the study was Giorgi's (1970; 1985; 2005; 2009; Giorgi \& Giorgi, 2003) descriptive phenomenological method, which sought to describe the meaning of lived experiences and allowed Indonesians to participate with the Canadian researchers from Indonesia via email. A qualitative methodology was selected because it provided the opportunity for the research participants to describe their own personal experiences of what it is like for them to work for Western-based organizations while still living at home.

Giorgi's descriptive phenomenological method was developed for the purpose of discovering and articulating "meanings being lived by research participants that reveal the nature of the phenomenon being researched" (Giorgi \& Giorgi, 2003, p. 252). Giorgi believed that a written (or verbal) description of a particular situation could form the basis of a research study when the focus is the meaning of these descriptions rather than the seeking of objective facts. The method includes specific ways of formulating research questions and explicit procedures for data collection and analysis/synthesis, as well, guidelines for participant sampling. As evidenced in the literature (Aquino-Russell, 2003; Baker, Arsenault, \& Gallant, 1994; Hetherington, 2002; Kraynie, 1985; Ng \& Sinclair, 2002; Purola \& Aavarinne, 2001; Russell, 2006), Giorgi's method provides rich data descriptions and insight into the unique experiences of persons who have lived the phenomenon under study.

\section{SAMPLING AND RESEARCH PARTICIPANT SELECTION}

This study involved 21 research participants who were "selected purposefully to permit inquiry into and understanding of the phenomenon" (Patton, 2002, p. 46). Silverman (2000), argued that "purposeful sampling allows us to choose a case because it illustrates some feature or process in which we are interested" (p.104). A participant must: have lived the experience the researcher is studying, be able to reflect, be articulate, and be willing to take part in the study (Denzin \& Lincoln, 1998). The participants were chosen on the basis that they:

\footnotetext{
- were Indonesian,

- $\quad$ have worked (or work) for a Western-based organization in Indonesia,

- $\quad$ were able to read and write in English, and

- $\quad$ were willing to write about their experiences and submit using email.
}

To maintain anonymity, pseudonyms were assigned to participants by the researchers to be used instead of real names in any reference in this paper.

The research participants were well-educated and had considerable experience in being employed by Western-based organizations located throughout Indonesia. They were men and women and together their employment experience totaled more than 35 different Western-based organizations. A wide variety of international non-government organizations (INGOs), transnational companies, and public service organizations were represented in the research participants' work experiences.

\section{DATA COLLECTION/ANALYSIS}

"The most straightforward way to go about ... research is to ask selected individuals to write their experiences down" (van Manen, 1990, p. 63). Thus, in this study, data in the form of written descriptions were collected from 21 research participants. This allowed the researcher to capture the descriptions precisely and in their entirety with no chance of imprecision as a result of transcription procedures. To initiate the actual data collection, each participant was invited via email to respond to the interrogatory statement: Please write about a situation or 
experience that best describes what it was like (or is like) for you to work for a Western-based organization in Indonesia. The statement was planned to draw out, without leading, the feelings and thoughts of the Indonesian employees (HCNs). They were advised to write as much, or as little, as they deemed appropriate. Following acceptance of the research participants' written descriptions, the researchers then undertook Giorgi's process (summarized by Aquino-Russell (2003)) as described and adapted in Table 1.

Table 1: Giorgi's Descriptive Phenomenological Method

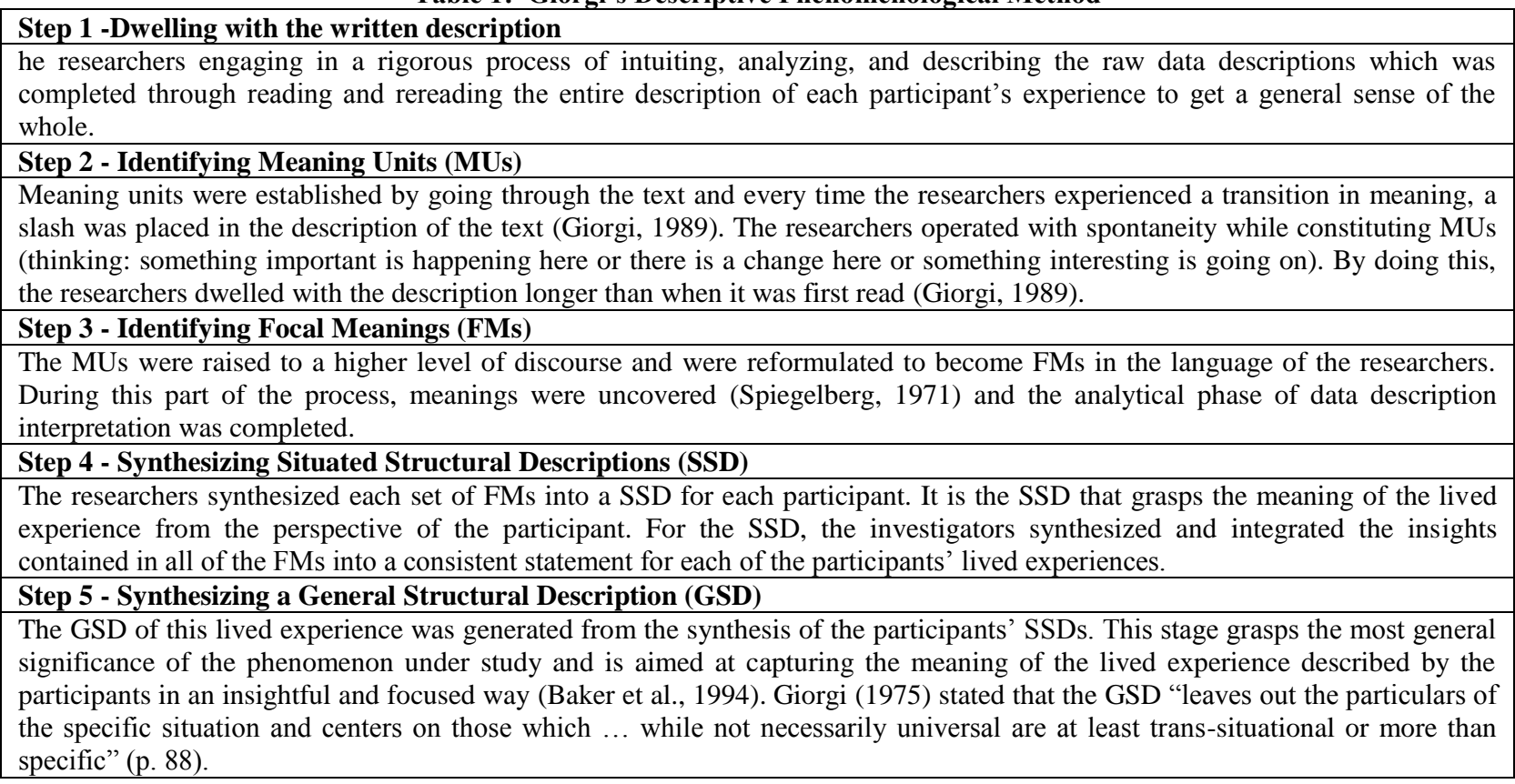

(Aquino-Russell, 2003, p.99-103)

\section{PRESENTATION OF DATA DESCRIPTIONS AND FINDINGS}

As noted in Step 5 above, the study was carried out to answer the research question: What is the general structural description (GSD) of The Meaning of the Experience of Indonesians Working for Western-Based Organizations at Home? Table 2 is included to enable the reader to discern the processes undertaken in Giorgi's method and to depict an example of MUs, FMs, and the SSD for one participant named Nanda (a researcherselected pseudonym). The same process was also undertaken with the data obtained from the other 20 participants. The GSD of this lived experience was generated from the synthesis of all 21 participants' SSDs and is presented immediately following Table 2 .

Table 2: The processes undertaken in Giorgi's method and to depict an example of MUs, FMs, and the SSD

\begin{tabular}{l}
\hline Meaning Unit \#2: Nanda \\
"Working in the international organization has exposed me to every possibility and good network, the salary paid was also \\
satisfying. Yes, we were working so hard to achieve our goal, but at the same time, we also got a well deserved remuneration. \\
This might be a reason why working in this such organization has a better bargaining position than working in the local company \\
or organization". \\
\hline Focal Meaning \#2: Nanda \\
$\begin{array}{l}\text { The benefits of remuneration and career growth in Western-based organizations outweigh those offered by Indonesian } \\
\text { organizations. }\end{array}$ \\
\hline Situated Structural Description for Nanda \\
$\begin{array}{l}\text { For this participant, working with Western-based organizations involved a reverse culture shock experience in learning to work } \\
\text { with others, from a different culture, who have high standards, time schedules, and results-based strategies. The benefits of } \\
\text { remuneration and career growth in Western-based organizations outweigh those offered by Indonesian organizations. The } \\
\text { participant emphasizes the importance of the need for Western managers to modify their behaviours towards local staff to fit in as } \\
\text { sometimes behaviours are inadequate. }\end{array}$ \\
\hline
\end{tabular}




\section{GENERAL STRUCTURAL DESCRIPTION - CENTRAL FINDING}

The GSD of this lived experience was developed from the synthesis of the participants' situated structural descriptions. This GSD, "leaves out the particulars of the specific situation and centers on those which, while not necessarily universal are at least trans-situational or more than specific" (Giorgi, 1975, p. 88). The central finding of this research (GSD) is the meaning of the experience.

For Indonesians working in Western-based organizations at home, time is paradoxically lived while being fairly-not fairly remunerated. Even with a results/outcomes focus on sustainability limits exist with decisions being made outside Indonesia. Respect/disrespect is experienced at work, depending on the management style while reverse culture shock is experienced when facilitating expatriate cultural immersion.

\section{DISCUSSION OF FINDINGS}

This phenomenological research uncovered the meaning of the lived experiences of Indonesians working for various Western-based organizations at home. In this discussion we will focus on one component of the findings that surfaced in many of the participants' data descriptions. This finding relates to the paradoxical feeling of Being Fairly /Not Fairly Remunerated as experienced by the participants. This paradox is expressed as: Remuneration is higher for HCNs than it would be for them working for local organizations, yet remuneration is less for Indonesians than it is for expatriates doing equal work. For HCNs, this difference may enliven feelings of being used while giving more than receiving and may result in a potential for staff demotivation, conflict, and envy for some participants, yet also enliven feelings of gratitude when comparing salaries of local organizations. It is noted that "paradoxes are not opposites, but are dimensions of the same rhythm lived all-at-once where one is in the foreground and one is in the background" (Parse, 1998, p. 30).

The paradoxical feelings of Being Fairly - Not Fairly Remunerated from the GSD are illuminated by selected direct quotations from the research participants' written descriptions are presented in Table 3.

Table 3: selected direct quotations from the research participants

\begin{tabular}{|l|l|}
\hline \multicolumn{1}{|c}{$\begin{array}{c}\text { Research } \\
\text { Participant }\end{array}$} & \multicolumn{1}{|c|}{ Direct Quotations from Research Participants' Descriptions of Experiences } \\
\hline Agus & $\begin{array}{l}\text { "For sure there is different amount of salary even the local staff have the same capacity in term of skills (even } \\
\text { in the same position)." }\end{array}$ \\
\hline Erika & $\begin{array}{l}\text { "The salary standard in local NGOs could not help me providing space for life improvement...I need this } \\
\text { international bodies to help my income." }\end{array}$ \\
\hline Gita & "There is health allowance and hospital reimbursement also." \\
\hline Jayadi & $\begin{array}{l}\text { "Working with Western-based organization is the aim of many local work seekers because they can practice } \\
\text { the English language and get higher payment." }\end{array}$ \\
\hline Misni & $\begin{array}{l}\text { "The big disparity of the local and Expat staffs salary even there is a big workload that has to be managed by } \\
\text { the local staffs sometimes leads to a jealousy, prone to the conflict, or declining commitment to work." }\end{array}$ \\
\hline Nanda & $\begin{array}{l}\text { "We were working so hard to achieve our goal, but at the same time, we also got a well deserved } \\
\text { remuneration." }\end{array}$ \\
\hline Oesman & $\begin{array}{l}\text { "...questions started to surface ... about the disparities between expatriate staff's salary and benefit packages } \\
\text { with national staffs. National staffs were paid less than \$400 per month but the expatriate were making 10 } \\
\text { times more than that, with tons of benefits, while most of the work was done by nationals." }\end{array}$ \\
\hline Ridwan & "[the] salary range [is] a lot better compared to others." \\
\hline Trisno & "It pays more than local companies (salary and benefit package) and also more challenging." \\
\hline Utami & $\begin{array}{l}\text { "As an employee I can say that multinational company (in my experience, western-based company) gives } \\
\text { more benefit and facility (in term of total amount and type of benefits) than local company." }\end{array}$ \\
\hline Verawai & "Remunerations--Above standards national company..." \\
\hline
\end{tabular}

Several research participants described the constant balancing act of experiencing harder lessons joined with higher remuneration from working with Western-based organizations as opposed to local organizations. Erika puts it best: 
Despite of all [successful] struggles in local NGO and idealism, I am now looking back for working in international NGO or companies (again), as I need better compensation for our life. The salary standard in local NGOs could not help me providing space for life improvement. So despite of all [difficult] lesson learnt I got from International NGOS or multinational company, I need this international bodies to help my income. (Erika-Research Participant)

The data descriptions from many research participants revealed a paradoxical reality of being paid less then expatriates for equal work, yet being paid more than fellow Indonesians working for local organizations. Agus described that salary was "not based on position but on your nationality" while Misni stated, "the big disparity of the local and Expat staffs salary even there is a big workload that has to be managed by the local staffs sometimes leads to a jealousy, prone to the conflict, or declining commitment to work." Oesman highlighted, astonishingly, that the expatriate made a salary ten times higher than that of the HCN which was what he called an "issue of disparity" in his workplace, made worse as it was "not uncommon for the Indonesians to do most of the work". Meanwhile, Ridwan and Verawati simply indicated that the higher pay obtained while working for Western-based organizations was a primary motivating factor for them to seek this kind of employment.

The question of benefits, which included health programs, training \& development, was very similar to salary in that it was generally higher than local organizations. However, there was a significant difference in that the higher benefits did not serve as lightening rod for discontent as did the large disparities in salary so was much less an issue for management. Gita supports this argument in her description:

Western-based organizations in Indonesia are really human care although it is very business minded. They will provide certain policy and procedure to make people feel safe and healthy. They really pay attention to the office surrounding and environmental. They always obey the Government rules also. Medical check up will always be held on every year for all the employee. There is health allowance and hospital reimbursement also.

Similarly, Lusino described excellent health benefits that were simply not offered in local organizations and Jiyadi wrote about the benefit of developing his English language skills which was huge to him and his colleagues. Misni, Agus, Misni, Utami, and Verawati were also clear in describing a high level of benefits from employment with Western-based organizations far outweighs what an Indonesian would receive as an employee for a local organization.

The research participants pointed to a much higher level of commitment to training and development programs as a result of their employment with Western-based organizations; however, there were contradictions as evidenced in the words of Agus when he stated: "I had not gotten knowledge transfer from the international staffs. Most of the time, I provided them with my knowledge". Yet more commonly described were positive perspectives such as this described by Ridwan: "they care about the employee's development, they provide us more in trainings or education" and from Dewi who wrote:

all organizations I had worked with made substantial effort to improve staff's capacity by providing internal training or allocating annual budget for self improvement. Organizations also took serious action in promoting staff who are valuable and had proved his/her working ability.

Others, including Imah, Kusnadi, and Bambang concurred that Western-based organizations were very committed to developing their personnel, most importantly, including their Indonesian personnel. Imah referred to it as "People Agenda" while Bambang expressed appreciation for being "pushed beyond his comfort zone". Kusnadi wrapped it up when he said:

The chances to interact with various experts, people from various backgrounds have helped in improving the selfconfidence and sharpen the critical thinking. By giving chances to national staffs to be in the position of field manager and some technical advisor, it is also the other way for building the capacity of the local people.

Overall, these findings point to the fact that the HCNs envisioned themselves as equal partners but they did not always feel equality especially in regards to remuneration levels. The fact that expatriate remuneration was substantially higher brought on some ill feelings but subsided somewhat with knowledge that their pay was higher 
than it would be if they worked in local organizations. Still the negative emotions and feelings of being trapped were being experienced or perceived by the research participants. For many, real satisfaction ensued from personal capacity and career development opportunities obtained as result of working with the Western-based organizations.

This research adds to the dearth of extant literature on the HCNs' perspective as opposed to ample literature focusing on Westerners who have expatriated to other countries. The findings serve to enhance overall knowledge in relation to the HNCs' feelings of Being Fairly /Not Fairly Remunerated while working for various Western-based organizations at home.

There is mention in the existing literature about salary disparities (Toh \& DeNisi, 2003) which matches with findings highlighted in this paper. Congruent is the belief that equal pay for equal work does not exist (Welch, 2003; Beaverstock, 2004). It is indicated that the expatriate salary is always higher and amazingly anywhere from three to twenty times higher than the HCN, who is employed in the exact same organization was typical (Reynolds 1997; Cervin \& Bonache, 2005).

It is not that HCNs are blind to the perceived unfair remuneration practices. For example, Misni said it can lead to "jealousy, prone to the conflict, or declining commitment to work." This is supported in the literature by researchers such as Mahajan (2011) who wrote, "pay policies follow an ethnocentric approach. They are perceived to be less acceptable and unfair by HCNs and thus may only elicit threshold behavior and compulsory cooperation from them (p.122)." Similarly, the HCNs see "injustice in remuneration, were more demotivated by the gaps, and were more likely to be thinking about leaving the organization (Marai, et al., 2010, p. 250).

Practitioners and researcher s should not be overlooking the $\mathrm{HCN}$ perspective in regards to remuneration. Lowe, Milliman, De Cieri and Dowling (2002) noted "most of what has been written on international compensation is focused exclusively on compensating the expatriate" (p. 47). As noted with the current findings, this will need to change as it is too important to ignore. It is also critical to remember that HCNs usually far outnumber expatriates in Western-based organizations (Bonache, Sanchez, \& Zarraga-Oberty, 2009) which implies the HCN perspective on pay satisfaction is essential (Black, Gregersen, \& Mendenhall 1992).

A bright spot in the findings and supported by Bonache et al. (2009) was that HCNs employed by Westernbased organizations do get paid higher than if they were employed in similar positions within local organizations.

\section{CONTRIBUTIONS AND RECOMMENDATIONS}

In an effort to enhance understanding of what it is like for Indonesians working in Western-based organizations at home, the study was designed to explore Indonesians' perspectives of the phenomenon by illuminating their lived experiences. The researchers expect understanding may lead to improvements in human resource management practices as well as strategies for facilitating and supporting the HCNs experience, thereby benefiting both Indonesians and the organizations that employ them. The findings also have implications which apply to a wide range of interests in the international management field including those of academic researchers and educators, human resource management professionals, senior managers, HCNs, and expatriates of the past, present, and future. Contributions and recommendations for human resource management practice follow.

\section{HUMAN RESOURCE MANAGEMENT PRACTICE}

It is clear that the management personnel of Western-based organizations need to be very concerned about the HCNs experience, particularly the perception of salary unfairness as it can impact employee productivity and, in turn, impact overall organizational performance.

International human resource management is a critical profession in light of globalization, especially when one considers the economic growth in large countries like China, India, and Indonesia. Equipped with an enhanced understanding of lived experiences of HCNs, there exists an excellent opportunity for human resource professionals to assist HCNs who may be overwhelmed by the paradoxical experiences and challenges involved in being employed by Western-based organizations, especially in Indonesia, which is very dissimilar to working in local organizations. 
Generally, current human resource practices related to HCNs have actually been mostly focused on expatriation. It is apparent, that HCNs are left largely to their own means and devices during their employment with the Western-based organization. This is not acceptable. Thus, it is recommended that the international manager and human resource professionals make frequent and regular contact with HCNs to find out what the experience is like for them. They need to listen and support the HCN given the reality of their employment experiences. It is about seeking to understand what the employee's experience is like and what would be helpful to make the extremes more manageable.

The lived experience of an HCN working in a Western-based organization is a highly individualistic experience. Employees' experiences must be understood in order to enact change to enhance their lived professional experiences. Standardized strategies are often used at present; however, experiences may be studied more easily and challenges improved by use of regular, qualitative research methods. Persons in the Western-based organization need to become more understanding and more aware of their own shortcomings in their relationships with HCNs. Thus, it is believed by the researchers that enhanced understanding emerging from this research study has the potential to alter the way that human resource professionals choose to deal with HCNs.

\section{CONCLUSION}

In today's world, there are ever-increasing numbers of persons living and working away from their home countries necessitating much interaction with HCNs working in Western-based organizations at the local level. As a result, HCNs obtain a wide variety of experiences and develop strong personal feelings while working in these organizations. To help individuals within the organizations to understand the complexities of the phenomenon, it is suggested that exploration of the experiences, feelings, and thoughts of HCNs be employed through seeking their descriptions of what it is like. This could be an important aspect of every staff meeting or team building session. HCNs have a tremendous amount of knowledge to share with human resource professionals and academics whose work will be aided with better understanding of the challenges of managing today's global workforce. Furthermore, the shared knowledge also will help present and former HCNs to make sense of their experiences, and through education and training, provide future HCNs with valuable insights into the nature of the employment experiences. As research participant -Erika said: “... working together the impossible becomes possible!”

\section{AUTHOR INFORMATION}

Dr. Roger Russell, BSc (Agr), MBA, Ph.D. Roger holds a Bachelor of Science degree (Agricultural Economics), University of Guelph, Guelph, Ontario; a Master of Business Administration, Saint Mary's University, Halifax, Nova Scotia, a Diploma in University Teaching, University of New Brunswick, Fredericton, New Brunswick, Canada; and a PhD in Business, Curtin University, Perth, Western Australia. Roger has been employed in several industries (agricultural, foodservice, financial, international development, and post secondary education) while working in five Canadian provinces and three countries (Canada, Indonesia, and Haiti). Currently, Roger is a professor, researcher, and administrator (Director of Professional Studies Division) at Crandall University, in Moncton, New Brunswick, Canada. E-mail: roger.russell@crandallu.ca. Corresponding author.

Dr. Catherine Aquino-Russell, RN, MN, Ph.D. Catherine completed a Bachelor of Nursing Science, Lakehead University, Thunder Bay, Ontario; a Masters in Nursing, University of Manitoba, Winnipeg; a Diploma in University Teaching, University of New Brunswick, Fredericton, New Brunswick, Canada; and a PhD in Nursing, Curtin University, Perth, Western Australia. She has held numerous education, leadership, volunteer, and administration positions in hospitals and universities in Canada and Indonesia. At present, she holds the positions of Associate Professor and BN Program Director at the Faculty of Nursing, University of New Brunswick, Moncton Campus, in Moncton, New Brunswick, Canada. E-mail: caquinor@unb.ca

\section{REFERENCES}

1. Aquino-Russell, C. E. (2003). Understanding the lived experience of persons who have a different sense of hearing. Doctoral dissertation, Curtin University of Technology, Perth, Australia. 
2. Aquino-Russell, C., \& Russell, R. (2009). Immersion in Another Culture: Paradoxical Experiences Considered for Teachers and Students in University Classrooms. Journal of Contemporary Issues in Education Research, 2(4), 77-86. ISSN: 1940-5847

3. Baker, C., Arsenault, A.M. \& Gallant, G. (1994). Resettlement without the support of an ethnocultural community. Journal of Advanced Nursing, 20, 1064-1072.

4. Banuta-Gomez, M. B. (2002). Leading and managing in developing countries: Challenge, growth and opportunities for twenty-first century organizations. Cross Cultural Management, 9(4), 29-41.

5. Bartlett, K., Lawler, J., Bae, J., Chen, S., \& Wan, D. (2002). Differences in international human resource development among indigenous firms and multinational affiliates in East and Southeast Asia. Human Resource Development Quarterly, 13(4), 383-405.

6. Beaverstock, J. (2004). Managing across borders: Knowledge management and expatriation in professional service legal firms. Journal of Economic Geography, 4(2), 157-179.

7. Black, J., Gregersen, H., \& Mendenhall, M. (1992). Global assignments. San Francisco, CA: Jossey-Bass.

8. Bonache, J., Brewster, C., \& Suutari, V. (2001). Expatriation: A developing research agenda. Thunderbird International Business Review, 43(1), 3-20.

9. Bonache, J., Sanchez, J., \& Zarraga-Oberty, C. (2009). The interaction of expatriate pay differential and expatriate inputs on host country nationals' pay unfairness. The International Journal of Human Resource Management, 20(10), 2135-2149.

10. Centre for Intercultural Learning. (2000). Indonesia: An introduction. Hull, PQ: Canadian Foreign Service Institute.

11. Cervino, J., \& Bonache, J. (2005). Hotel management in Cuba and the transfer of best practices. International Journal of Contemporary Hospitality Management, 17(60), 455-468.

12. Denzin, N. K., \& Lincoln, Y. S. (1998). Collecting and interpreting qualitative materials. Thousand Oaks, CA: Sage Publications.

13. Giorgi, A. (1970). Psychology as a human science. A phenomenologically based approach. New York: Harper \& Row.

14. Giorgi, A. (1975). An application of phenomenological method in psychology. In A. Giorgi, C. Fischer \& E. Murray (Eds.), Duquesne studies in phenomenological psychology (Vol. II). Pittsburgh: Duquesne University Press.

15. Giorgi, A. (1985). Phenomenology and psychological research. Pittsburgh: Duquesne University Press.

16. Giorgi, A. (1989). One type of descriptive data: Procedures involved in following a systematic phenomenological method. Annual Edition of Methods: A Journal for Human Science, 39-61.

17. Giorgi, A. (2005). The phenomenological movement and research in the human sciences. Nursing Science Quarterly, 18 (1), 75-82.

18. Giorgi, A. (2009) The descriptive phenomenological method in psychology: A modified Husserlian approach. Pittsburgh: Duquesne University Press.

19. Giorgi, A. P., \& Giorgi, B. M. (2003). The descriptive phenomenological psychological method. In P. M. Camic, J. E. Rhodes \& L. Yardley (Eds.), Qualitative research in psychology: Expanding perspectives in methodology and design. Washington, DC: American Psychological Association.

20. Government of Canada. (2010). Foreign Affairs and International Trade. Retrieved from: http://www.international.gc.ca/trade-agreements-accords-commerciaux/agr-acc/fipa-apie/indonesiaindonesie.aspx. January 10, 2010.

21. Hawkins, S. (1983). How to understand your partner's cultural baggage. International Management, 38 (9), 48-51.

22. Hetherington, D. (2002). Disaster trauma: A phenomenological-linguistic analysis of Buffalo Creek flood accounts (West Virginia). Dissertation Abstracts International, 63 (2-B), 1029.

23. Hutchings, K. (2005). Koalas in the land of the pandas: Reviewing Australian expatriates' China preparation. International Journal of Human Resource Management, 16(4), 553-566.

24. Keen, E. (1975). A primer in phenomenological psychology. New York, NY: Holt, Rinehart and Winston

25. Kraynie, L. K. (1985). The lived experience of persisting in change: A phenomenological study. In R. R. Parse, A. Coyne \& M. Smith (Eds.), Nursing research: Qualitative methods. Bowie, MD: Brady Communications. 
26. Lee, L., \& Sukoco, B. (2010). The effects of cultural intelligence o expatriate performance: the moderating effects of international experience. The International Journal of Human Resource Management, 21(7), 963981.

27. Loiselle, C. G., \& Profetto-McGrath, J. (2004). Canadian essentials of nursing research. Philadelphia: Lippincott Williams \& Wilkins.

28. Lowe, K., Milliman, J., De Cieri, H., \& Dowling, P. (2002). International compensation practices: A ten country comparative analysis. Asia Pacific Journal of Human Resource, 40(1), 55-80.

29. Mahajan, A. (2011) Host country national's reactions to expatriate pay policies: making a case for a cultural alignment pay model. The International Journal of Human Resource Management, 22(1), 121-137

30. Marai, L., Kewibu, V., Kinkin, E., Peniop, J., Salini, C., \& Kofana, G. (2010). Remuneration disparities in Oceania: Papua New Guinea and Solomon Islands. International Journal of Psychology, 45(5), 350-359.

31. Mendenhall, M., Kuhlmann, T., Stahl, G., \& Osland, S. (2002). Employee development and expatriate assignments. In M. J. Gannon \& K. L. Newman (Eds.), The blackwell handbook of cross-cultural management. Oxford, UK: Blackwell Publishers Inc.

32. Mendenhall, M., Punnett, B., \& Ricks, D. (1995). Global management. Cambridge, MA: Blackwell.

33. Montagliani, A., \& Giacalone, R. (1998). Impression management and cross-cultural adaption. The Journal of Social Psychology, 138(5), 598-608.

34. Ng, M., \& Sinclair, M. (2002). Women's experience of planned home birth: A phenomenological study. RCM Midwives Journal, 5(2), 56-59.

35. Osland, J. S. (2000). The journey inward: Expatriate hero tales and paradoxes. Human Resource Management, 39(2, 3), 227-238.

36. Osland, J., \& Osland, A. (2006) Expatriate paradoxes and cultural involvement. International Studies of Management and Organizations, 35(4), 91-114

37. Owen, J. (2010). 'Listening to the rice grow': The local-expat interface in Lao-based international NGOs. Development in Practice, 20(1), 99-112.

38. Parse, R. R. (1998). The human becoming school of thought. A perspective for nursing and other health care professionals. London: Sage Publications.

39. Patton, M. Q. (2002). Qualitative research \& evaluation methods (3rd ed.). Thousand Oaks, CA: Sage.

40. Purola, H., \& Aavarinne, H. (2001). Phenomenologic research process in nursing science: Experiences of home dwelling stroke patients and their relatives about coping. Hoitotiede, 13(2), 68-77.

41. Peppas, S. C. (2004). Making the most of international assignments: A training model for non-resident expatriates. Journal of American Academy of Business, 5(1, 2), 41-45.

42. Reynolds, C. (1997). Expatriate compensation in historical perspective. Journal of World Business, 32(2), 118-132.

43. Romyn, D. (2001). Disavowal of the behaviourist paradigm in nursing education: What makes it so difficult to unseat? Advances in Nursing Science, 23(3), 1-10.

44. Russell, R. (2006) Expatriate managers' immersion in another culture: A phenomenological study of lived experiences. Doctoral Dissertation. Curtin University of Technology, Perth, Australia.

45. Russell, R., \& Aquino-Russell, C. (2010). “Expatriate Managers: Powerful or Powerless?” International Journal of Business \& Economics Research, 9(2), 101-108

46. Russell, R., \& Aquino-Russell, C. (2011). Living and working between two worlds: Using qualitative

47. Phenomenological findings to enhance understanding of lived experiences. In S. Mariano, M. Mohamed \& Q. Mohiuddin, The role of expatriates in MNCs knowledge mobilization.

48. Bingley, UK: Emerald Publishing.

49. Russell, R., \& Dickie, L. (2007). "Paradoxical experiences of expatriate managers in Indonesia". Journal of Diversity Management, 2(1), 17-28.

50. Selmer, J. (2000). Usage of corporate career development activities by expatriate managers and the extent of their international adjustment. International Journal of Commerce \& Management, 10(1), 1-23.

51. Shim, I.-S., \& Paprock, K. E. (2002). A study focusing on American expatriates' learning in host countries. International Journal of Training and Development, 6(1), 13-24.

52. Silverman, D. (2000). Doing qualitative research: A practical handbook. Thousand Oaks, CA: Sage.

53. Spiegelberg, H. (1971). The phenomenological movement: A historical introduction (2nd ed. Vol. II). The Hague: Martinus Nijhoff. 
54. The Indonesia Canada Chamber of Commerce. (2000). Indonesia-Canada: Into the new millennium. Jakarta: The Embassy of Canada.

55. Takeuchi, R. (2010). A critical review of expatriate adjustment research through a multiple stakeholder view: Progress, emerging trends, and prospects. Journal of Management, 36(4), 1040-1064.

56. Tarique, I., Schuler, R., \& Gong, Y. (2006). A model of multinational enterprise subsidiary staffing composition. The International Journal of Human Resource Management, 17(2), 207-224.

57. Templar, K. (2010). Personal attributes of expatriate managers, subordinate ethnocentrism, and expatriate success: A host-country perspective. The International Journal of Human Resource Management, 21(10), 1754-1768.

58. Toh, S., \& DeNisi, A. (2003). Host country national reactions to expatriate pay policies: A model and implications. Academy of Management Review, 28(4), 606-621.

59. Tung, R. L. (1988). Career issues in international assignments. The Academy of Management Executive, 2(3), 241-244.

60. Vance, C., Vaiman, V. \& Andersen, T. (2009). The vital liaison role of host country nationals in MNC knowledge management. Human Resource Management. 48(4), 649-659.

61. van Manen, M. (1990). Researching lived experience: Human science for an action sensitive pedagogy. London, Canada: The Althouse Press, University of Western Ontario.

62. Varma, A., Pichler, S., \& Budhwar, P. (2011). The relationship between expatriate job level and host country national categorization: An investigation in the UK. The International Journal of Human Resource Management, 22(1), 103-120.

63. Varner, I. I., \& Palmer, T. M. (2002). Successful expatriation and organizational strategies. Review of Business, 23(2), 8-11.

64. Vo, A. (2009). Career development for host country nationals: a case of American and Japanese multinational companies in Vietnam. The International Journal of Human Resource Management, 20(6), 1402-1420.

65. Welch, D. (2003). Globalization and staff movements: Beyond cultural adjustment. Management International Review. 43(2), 149-169. 
\begin{tabular}{ll} 
International Journal of Management \& Information Systems - Third Quarter $2012 \quad$ Volume 16, Number 3 \\
\hline
\end{tabular}

NOTES 